\title{
GSP05
}

\section{Innovative Use of Real Time Density Image in Well Placement}

\author{
O. BABAYEJU* (Schlumberger), E. Brentjens (ADDAX), L. Clegg (ADDAX), \\ M. Idris (ADDAX), S. Oloniboko (ADDAX), D. Nwabor (Schlumberger), I. \\ Jumbo (Schlumberger) \& G. Santoso (Schlumberger)
}

\section{SUMMARY}

Optimizing reservoir contact whilst drilling a single developmental well within two targets separated by an impervious shale layer, presented a sea of geological and drilling challenges.

Drilling a long reach lateral drain section in a velocity uncertain; structurally complex and probably faulted reservoir with poor control towards the toe was expected to be challenging. This paper will highlight how effective interpretation of RT ADN image with high confidence structural modification by Real Time Geosteering Screen (RTGS) aided the highly successful geosteering of Well-A horizontal well. This includes the planning of Well-B; the reduction of structural uncertainties and the successful drilling of Well-B with increased length of the drain section and increased N/G.

With the use of conventional Well Placement with ADN density real -time image from InterACT, the lateral section was optimized in the two lobed targets. With the integration of structural information derived from the real-time ADN image data for Well-A, Well-B horizontal well was planned to near perfection. While drilling Well-B, there was little or no need for geosteering, as the well had no reason to deviate from the plan, hence the close match between actual and planned trajectories. 
Optimizing reservoir contact whilst drilling a single developmental well within two targets separated by an impervious shale layer, presented a sea of geological and drilling challenges.

Drilling a long reach lateral drain section in a velocity uncertain; structurally complex and probably faulted reservoir with poor control towards the toe was expected to be challenging. This is why Addax Petroleum Nigeria Limited was willing to engage the services of Schlumberger.

This paper will highlight how effective interpretation of RT ADN image with high confidence structural modification by Real Time Geosteering Screen (RTGS) aided the highly successful geosteering of Well-A horizontal well. This includes the planning of Well-B; the reduction of structural uncertainties and the successful drilling of Well-B with increased length of the drain section and increased N/G.

With the use of conventional Well Placement with ADN density real -time image from InterACT, the lateral section was optimized in the two lobed targets. An $81 \% \mathrm{~N} / \mathrm{G}$ was achieved, mainly reduced by the 6-8 ft thick intra-reservoir shale separating the twolobes. A total horizontal section of about $2300 \mathrm{ft}$ MD was drilled, with $1850 \mathrm{ft}$ of this in clean sand. Using ADN RT image data, the Well Placement team was able to re-model the structure of this complex and highly undulated reservoir. As a result of this, the team was able to deliver excellent N/G result for Well-A. The interpreted structural model was also an input for updating Addax's Geological Model.

With the integration of structural information derived from the real-time ADN image data for Well-A, Well-B horizontal well was planned to near perfection. While drilling Well-B, there was little or no need for geosteering, as the well had no reason to deviate from the plan, hence the close match between actual and planned trajectories. The lateral section was optimized in the three lobed targets. An $83 \% \mathrm{~N} / \mathrm{G}$ was achieved, mainly reduced by the $13.71 \mathrm{ft}$ thick intra-reservoir shale separating the three lobes. A total horizontal section of about $2384 \mathrm{ft}$ MD was drilled, with $1978 \mathrm{ft}$ MD of this in clean sand. 